\title{
Current therapy for retinal vein occlusion
}

\author{
Cernak M, Struharova K \\ Ophthalmic Department, University Hospital Cyril and Metod, Bratislava, Slovakia. \\ cernakmartin@yahoo.co.uk
}

\begin{abstract}
Retinal vein occlusion is a common retinal vascular disorder causing visual deterioration in the elderly. Vision-threatening complications include macular ischemia, neovascularisations, and vitreous hemorrhages. There are central and branch retinal vein occlusions as well as their ischemic and nonischemic subtypes. Branch occlusion and nonischemic cases are associated with better prognosis, often with good recovery of visual acuity. There have been various modes of therapy used for this disease but with little or poor effect. Due to the lack of effective monotherapy for retinal vein occlusions, there is probably a need to combine the therapy approaches (Fig. 4, Ref. 24). Full Text in PDF www.elis.sk.

Key words: retinal vein occlusion, ischemia, corticosteroids, anti-VEGF.
\end{abstract}

Retinal vein occlusions (RVO) is the second most common retinal vascular disorder after diabetic retinopathy causing mild to serious visual deterioration in the elderly (1). RVO often occurs suddenly, with painless loss of vision in the affected eye. Macular edema is the major cause of vision impairment in these patients.

Other vision-threatening complications are macular neovascularizations and vitreous hemorrhages. Risk factors include advanced age, hypertension, atherosclerosis, diabetes mellitus, and hypercholesterolemia.

There are two main subtypes of RVO, namely central retinal vein occlusion (CRVO) and branch retinal vein occlusion (BRVO) which differ by location of obstruction. In CRVO, the central retinal vein is obstructed in the site of its passage through lamina cribrosa of the optic nerve and the obstruction affects most of the retina.

In BRVO, a branch of the central retinal vein is obstructed and a quadrant or part of the fundus is typically affected (2).

The prevalence of BRVO (0.6 \% to $1.6 \%)$ is greater than that of CRVO (0.1\% to $0.4 \%$ ) (3). Retinal vein occlusions (CRVO and BRVO) present as ischemic or nonischemic types. Ischemic RVO documented on fluorescein angiography presents typically with 10-disc diameter or more of capillary nonperfusion. This is associated with a serious impairment of visual acuity and a poor prognosis of achieving vision of 20/200 or worse. Vascular endothelial growth factor (VEGF) is released by ischemic retina and causes excessive vascular permeability.

Nonischemic cases are associated with better prognosis, while the vision often recovers to 20/40 or better. Vision- threatening complications associated with RVO include vitreous hemorrhage, macular edema, macular ischemia, or neovascularization.

Ophthalmic Department, University Hospital Cyril and Metod, Bratislava, Slovakia

Address for correspondence: $\mathrm{M}$. Cernak, $\mathrm{MD}, \mathrm{PhD}$, Ophthalmic Department, University Hospital Cyril and Metod, Antolska 11, SK-851 07 Bratislava, Slovakia.

Phone: +421.2.68672039
Final visual acuity (VA) after RVO is strongly dependent on visual acuity at presentation (4).

\section{Treatment for retinal vein occlusion}

Until now, there has been no study to prove efficacy for either thrombolytic or antiagregans therapy (5).

Laser treatment for RVO-associated macular edema and retinal neovascularization was first introduced in 1976 (6).

In CRVO, panretinal photocoagulation (PRP) is an effective treatment for neovascularization, nevertheless an earlier study of PRP for neovascularization of ischemic CRVO showed no treatment benefit (11). Grid photocoagulation for macular edema was shown to be effective in BRVO but not in CRVO. Laser-induced chorioretinal anastomoses, although still in use, are associated with significant treatment risks (hemorrhages) without significant improvement in prognosis (7).

More recently, intravitreal medications, such as anti-VEGF agents, have been used to treat macular edema associated with RVO (8).

Within the recent years, several studies have reported positive effects after treatment with bevacizumab (Avastin, Genentech Inc.) or ranibizumab (Lucentis, Genentech, Inc.). Both drugs are vascular endothelial growth factor (VEGF) inhibitors used by retina specialists for a variety of retinal diseases, mostly exudative agerelated macular degeneration (ARMD). There has been growing interest in using it for retinal vein occlusions (RVO). It is unclear how long and how frequent the treatments should be administered. The timing, inconvenience, risks, and costs of injections are some of issues favoring less frequent dosing regimens. However, the results from randomized controlled trials have not yet been published, and the treatment effects may be temporary.

IVB (intravitreal Bevacizumab) seemed to significantly affect the natural history of nonischemic RVOs. Many patients responded with initial vision improvement (71\% for BRVO and 56\% for 




Fig. 1.

CRVO), and most of the improvement seen occurred after the first injection. With treatment on as-needed basis, there was regression from the best achieved vision to final vision in all patients but the regression occurring in patients with CRVO was greater than in those with BRVO. Nevertheless, even with this regression, the improvement from baseline was still significant. Patients with CRVO seemed to require more frequent injections (9).

The data seem to suggest that all patients would likely do better with more frequent maintenance injections, much like the results seen in patient with ARMD.

This study is limited by its retrospective design and nonstandardized follow-up. Patients would likely have done even better with an as-needed approach if the monthly follow-up had been strictly maintained. Based on this study and experience, our practice pattern has been shifted to more frequent examinations with an as-needed approach or regular maintenance injections for patients who wish to visit less often or monocular patients. Further study is warranted but this treatment seems to improve the outcomes of patients suffering from retinal venous occlusive disease.

Intravitreal triamcinolone (IVTA) and other corticosteroids have also been effective in several studies, including randomized controlled trials. Although intravitreal corticosteroids are associated with significant side effects such as the increase in intraocular pressure or cataract formation, they remain a therapeutic approach for the treatment of RVO.

Due to the lack of effective monotherapy for RVO, there is a need to combine the therapy approaches.

\section{Combination therapy with BEVACIZUMAB and intravitreal triamcinolon acetate (IVTA)}

Although there are no randomized controlled trials testing the efficacy of combining IVTA and bevacizumab for RVO currently in place, there are preliminary indications that this approach might be more effective. In one published case report, an individual with CRVO and chronic macular edema responding neither to IVTA nor to bevacizumab was treated effectively by simultaneous administration of both drugs (10). This observation is supported by results from an uncontrolled case series of 13 eyes with macular edema due to RVO, while the patients exhibited a mean gain of 5.5 letters in VA and a mean reduction in retinal thickness of

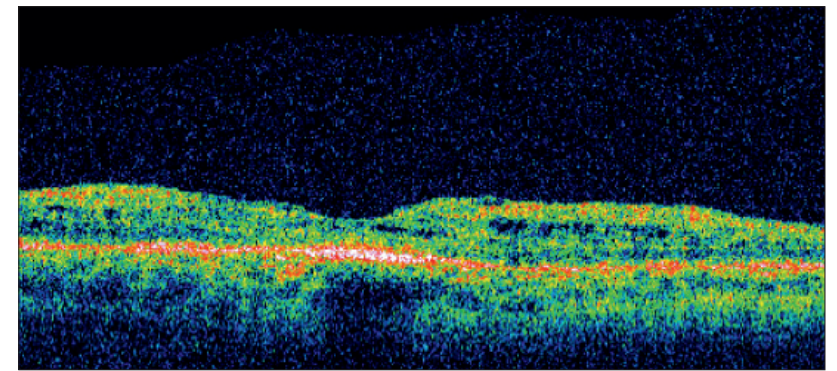

Fig. 2.

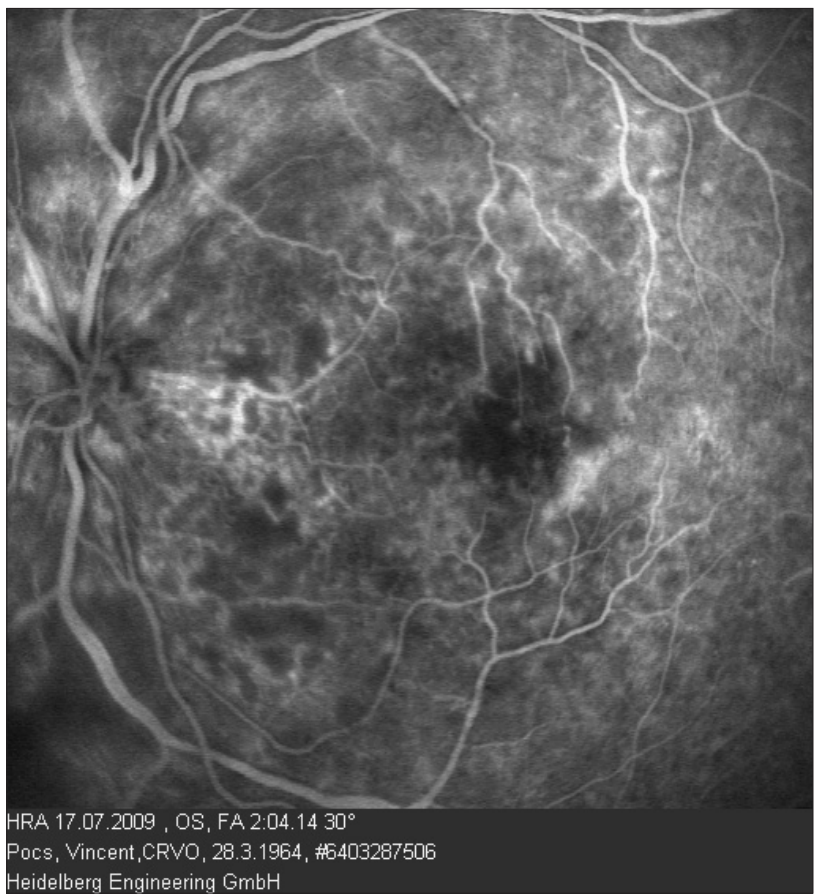

Fig. 3.

$187 \mathrm{pm}$ after receiving the IVTA/Avastin combination (11). Two small randomized controlled trials comparing this combination to bevacizumab monotherapy in 25 patients with CRVO are listed on the website of ClinicalTrials.gov $(12,13)$. None of these listings, however, has been updated in over a year, and the results have not been reported even though both studies have passed their estimated completion dates.

\section{Laser/IVTA combination therapy}

The studies included two case series in which improved central retinal thickness was observed. However, two randomized controlled trials yielded mixed results. In one study, 25 eyes received IVTA alone and 12 eyes received IVTA and grid photocoagulation (14). A significant but short-lived reduction in central retinal thickness was observed in both treatment groups but the IVTA 


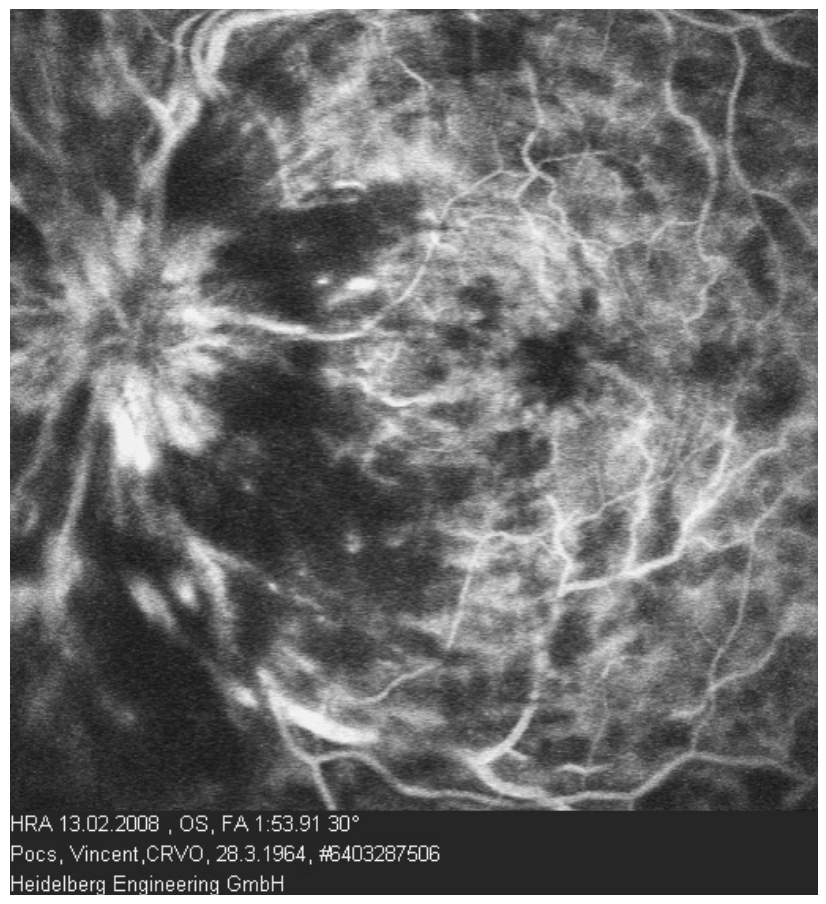

Fig. 4.

monotherapy group had a greater improvement in visual acuity (VA). In the other study, 24 patients were randomized to receive IVTA with subthreshold grid laser photocoagulation (SGLT) or SGLT alone (15). After one year of follow-up, the combination group exhibited a significantly improved VA relative to baseline while the laser-only group did not. These reports suggest that the photocoagulation/IVTA combination may be beneficial but it is not yet clear whether this therapy is more effective than IVTA alone because no treatment benefit was shown in the trial comparing laser/IVTA to IVTA alone.

\section{Surgical/IVTA combination therapy}

A variety of surgical/IVTA combination therapy reports were reviewed, including three publications, one listed at ClinicalTrials.gov, and five ARVO presentations. In a case series, 63 eyes received radial optic neurotomy (RON) and IVTA for CRVO, and VA improved by a mean of three lines in $68 \%$ of patients (16). Similar results were observed in a separate case series of 117 patients who received RON alone (17). In another series, 22 eyes received RON/IVTA, and eight eyes received RON alone (18). A significant improvement in VA was observed in the RON-alone group but not in the combination group. In both studies, the group receiving IVTA had a higher incidence of ocular adverse events. Neither study demonstrated any treatment benefits for the adjunctive use of IVTA with RON. Another combination that has been investigated in several studies is IVTA and vitrectomy.

Although improved VA was observed in eyes receiving this combination in two uncontrolled longitudinal studies, a significant treatment effect was observed in neither of these two randomized controlled trials (19). In an ongoing study, 47 eyes with CRVO or BRVO received vitrectomy with IVTA and bevacizumab (20). A study of the combination of hemodilution with IVTA has also been reported. Thirty eyes with CRVO were randomized to receive hemodilution or hemodilution/IVTA, and combination-treated eyes exhibited improved VA and reduced macular thickness relative to eyes treated with hemodilution alone (21). In a study comparing maculopexy assisted by gas and/or triamcinolone, BRVO eyes receiving gas-assisted maculopexy exhibited greater improvement than eyes receiving triamcinolone-assisted maculopexy (22). Additional combinations reported include vitrectomy, arteriovenous sheathotomy and IVTA (23), and RON with internal limited membrane (ILM) peeling and IVTA (24).

Out of the reviewed combination of therapies, the combination of IVTA and bevacizumab appears to be promising. At the present time however, the data to support this hypothesis are limited. Randomized controlled trials are under way.

\section{References}

1. Central Vein Occlusion Study Group. Baseline and early natural history report. The Central Occiis on Study. Arch Ophthalmol 1993; 111: 1085-1095.

2. Rehak J Rehak M. Branch retinal vein occlusion pathogenesis, visual prognosis and treatment modalities. Corr Eye Res 2008; 33 (2): 111-131.

3. Ryan SJ. Retina. Philadelphia: Elsevier Mosby, 2006, 3: 1339-1354.

4. The Central Vein Occlusion Study Group. Natural history and clinical management of central retinal vein occlusion. Arch Ophthalmol 1997; 115 (4): 486-491.

5. Hayreh SS. Venous occlusive disease. Management 25 years ago. Retina 2006; 26 (Suppl 6): S51-S62.

6. The Central Vein Occlusion Study Group. Evaluation of grid pattern photocoagulation for - acular edema in central vein occlusion. The Central Vein Occlusion Study Group M Report. Ophthalmology 1995; 102 (10): 1425-1433.

7. The Branch Vein Occlusion Study Group. Argon laser photocoagulation for macular edema urh vein occlusion. Am J Ophthalmol 1984; 98: 271-282.

8. Costa RA, Jorge R, Calucci D Melo LA Jr, Cardillo JA, Scott IU. Intravitreal bevacizumab (Avastin) for central and hemicentral retinal vein occlusions. IBeVO study. Retina 2007; 27: 141-149.

9. Iturralde D, Spaide RF, Meyerle CB et al. Intravitreal bevacizumab (Avastin) treatment of macular edema in central retinal vein occlusion. A short-term study. Retina 2006; 26: 279-284.

10. Ekdawi NS, Bakri SJ. Intravitreal triamcinolone and bevacizumab combination therapy for macular edema due to central retinal vein occlusion refractory to either treatment alone. Ere 2007; 21 (8): 1128-1130.

11. Offerman I Scholl S, Augustin A. Treatment of diabetic macular edema and edema due to retinal vein occlusion with Intravltreal bevacizumab and tiamcinolone aceronide. Invest Ophthalmol Vis Sci 2008; 49E: Abstract 2713.

12. Intravitreal Avastin Versus Intravitreal Avastin and Triamcinolone in Central Retinal Vein Occlusion (CRVO). Available at http://www. clinicaltrialsgovl/ct2/shovv/NCT00370630. Accessed on February 5, 2009. 
13. Treatment of Bevacieurnals and Triamcinolone in Treatment or Macular Edema Secondary to CRVO (MECROV). Available at http// www.clinicaltuals.gov/c(2/show/NCT0056676I Accessed on Accessed on February, 2009.

14. Cakir M, Sagan M, Baynalklar Z et al. Efficacy of Intravitreal triamcinolone for the treatment of macular edema secondary to branch retinal vein occlusion in eyes with or without grid laser photocoagulation. Retina 2008; 28 (3): 465-472.

15. Parord MB, Iacono P Ravalico G. Intravitreal triamcinolone acetionice combined with subthreshold grid laser treatment for macular oedema in branch retinal vein occlusion a pilot study. Br J Ophthalmol 2008; 92 (8): 1046-1050.

16. Opremcak EM, Rehmar AJ, Ridenour CD, Kurz DE, Borkowski LM. Radial optic neurotomy with adjunctive untraocular triamcinolone for central retinal vein occlusion: 63 consecutive cases. Retina 2006; 26 (31): 306-313.

17. Opremcak EM, Rehmar AJ, Ridenour W, Kurz DE. Radial optic neurotomy fur central retinal vein occlusion. 117 consecutive cases. Retina 2006; 26 (3): 297-305.

18. Oono Y, Tsuru H, Teruya K et al. Long-term outcomes of radial optic neurotomy with or without adjunctive intraocuiartriamclnolone acetonide in central retinal vein occlusion. Invest Ophthalmol Vis Scr 2008; 49 E: Abstract 4692.
19. Ma J, Yao K Zhang Z, Tang X. 25-gauge vitrectomy and triamcinolone acetonide-assisted internal limiting membrane peeling for chronic cystoid macular edema associated with branch retinal vein occlusion. Retina 2008; 28 (7): 947-956.

20. Combined Triple Procedure in Retinal Vein Occlusion (RVO). Available at http//www.clinical study.

21. Serny C, Mura F, Rebollo B., Arnaud B, Arndt C. Hemodilution with and without triamcinolone at the initial phase of vein occlusion: A retrospective comparative study. Invest Ophthalmol Vis Sci 2007; 48 E: Abstract 298.

22. Lewis GM, Morris R. Treatment of cystoid macular edema in branch retinal vein occlusion with grid photocoagulation, intravitreal triamcinolone, and pneumatic maculopexy. Invest Ophthalmol Vis Sci 2006; $47 \mathrm{E}$ : Abstract 5207.

23. Kim E, Koreen S, Fine HF, Change S, Delpriore L. Combined arteriovenous sheathotomy and intraoperative intravitreal triamcinolone acetonide for branch retinal vein occlusion. Invest Ophthalmol Vis Sci 2008; $49 \mathrm{E}$ : Abstract 5982.

24. Ferrari TM, Sborgia L, Furino C, Reibaldi M, Ferreri P, Sborgia C. Radial optic neurotomy, internal limiting membrane peeling and intravitreal triamcinolone in the occlusion of the central retinal vein occlusion. Invest Ophthalmol Vis Sci 2004; 45 E: Abstract 5219.

Received July 14, 2010. Accepted January 13, 2012. 